\title{
The Design and Practice of "Flipped Classroom" Model Based on Task-driven and Micro-lecture
}

\author{
Yin Hong-li \\ The College of Science \\ Qilu University of Technology \\ Jinan, Shandong, P.R.China \\ e-mail: yhl@qlu.edu.cn
}

\begin{abstract}
Flipped classroom" teaching model has became the focus of global education and has yielded many promising and important results. For the critical issue of the implementation of "Flipped Classroom" model, this article explores "Flipped Classroom Model" and verifies the effects of this teaching model in practice on the basis of the existing resources and activities of task-driven and micro-lecture from home and abroad. This model combined with the specific course of JAVA Programming and the practice shows that this model has a certain degree of success in the application.
\end{abstract}

Keywords: task-driven; micro-lecture; flipped classroom;

\section{INTRODUCTION}

Flip teaching or a flipped classroom is a form of blended learning in which students learn new content online by watching video lectures, usually at home, and what used to be homework is now done in class with teachers offering more personalized guidance and interaction with students, instead of lecturing. This is also known as backwards classroom, inverted classroom, flipped classroom, reverse teaching [1].

In American, the flipped classroom has been deeply researched and many research findings have been accumulated. Recently, many education practitioners have been applying the flipped classroom to the educational practices according to different subjects, different types of courses. After a period of classroom practice, they have achieved good teaching effect. As regards the application of flipped classroom in university and college, the MS Excel course in Brigham young university and the system control course in department of mechanical engineering at the University of Seattle have made obvious effect after practice of flipped classroom[2][3]. In China, scholars also have begun to combine courses to demonstrate the effectiveness of specific application mode.

Moreover, flip classroom is widely used in computer course. The flipped classroom teaching complies with the demand of the computer course which pays more attention to students' ability of the self-study and practice. In department of computer science and systems analysis at Miami University, the teachers, Gerald C. Gannod, Janet E. Burge and Michael T. Helmick, applied the flipped classroom to courses "software engineering", "data structure" and "programming".
However, the research about the flipped classroom more focused on the concept, exploratory, strategic in China. Obviously, the existing research neglected the design and research of the knowledge transfer. To achieve the integration of before-class, in-class and post-class activities, the key of implementation of flipped classroom is the link before-class, in-class, post-class activities. In this paper, combined with my own teaching practice, "flipped classroom" teaching model based on task-driven and microlecture is proposed.

\section{The Design OF "FliPPED ClASSROOM" TEACHING MODEL BASED ON TASK-DRIVEN AND MICRO-LECTURE}

\section{A. the Situation Analysis}

At present, the Java programming course is as a professional elective for students of computer science in most universities. The purpose of Java programming course is to help students to build object-oriented programming ideas, master the basic syntax of Java and to be equipped with certain procedures design capabilities.

The traditional teaching methods are only emphasized the systematicness and integrity of the theory, they don't have enough attention to experiments, and resulting in the separation of theoretical and practical. Students in the learning process generally felt that the programming language is abstract and difficult to understand. It leads to losing interest and confidence on the programming. This shows that the traditional teaching methods are not suitable for teaching of programming languages. We need to reform and explore the teaching mode of Java programming.

In order to implement the mode of flipped classroom, we conducted interviews and a questionnaire survey to undergraduates of grade 2010 majoring in Computer Science. The total number of students of grade 2010 majoring in computer science is 75 . The questionnaire issued 72 copies, 70 were recovered. The results of the questionnaire show that there appeared many problems in the pre-class stage, such as "how to learn", "why study" and the concentration problems in the process of students' autonomous learning phase.

\section{B. The meaming of task-driven}

Task-driven can stimulate student's interest of study and improve students' ability of thought and application [4]. In 
this process, teachers are the organizers; instructors, assistor and promoter facilitator, and the students will exert their initiative, enthusiasm and creativity by the use of microlecture video, collaboration, conversation and other elements of the learning environment. At last, students achieve effective construction of the learned knowledge. The main characteristics of task-driven teaching are to complete task in practice. Thus, the method is suitable for JAVA programming course [6], because the curriculum is a highly practical curriculum, which requires students not only to learn the theoretical knowledge, but also to master the practical skills. At the same time, the students are required to possess some abilities, such as self-study, independent analysis of issues and problem-solving due to the knowledge of JAVA programming updated very quickly.

\section{The meaming of micro-lecture}

Research shows that, students concentrate on learning only 5-10 minutes. Micro-lecture which limits the length of the video in this range can ensure that students pay the most attention to learning content [5]. Moreover, micro-lecture can make the students focus on a certain topic in a short time, and promote understanding of some key concepts which was difficult. It can improve the teaching efficiency greatly as an important teaching resource. The video of micro-lecture is short, so the way of presentation avoids the students feel boring or unable to concentrate on video learning. The micro-lecture teaching videos become the preferred mobile teaching resources because that it is accordance with mobile teaching idea of leaning "whenever and wherever ". This would solve the concentration problems in the process of students' autonomous learning phase.

\section{D. "Flipped Classroom" Teaching Model Based on Task- driven and Micro-lecture}

The Robert Talbert flipped classroom model [1] is "learning before teaching", including "activities before classroom " and "classroom activities" two each other to link. The traditional classroom knowledge was transferred to complete before class, knowledge internalization after classroom activities originally was transferred to the classroom learning activities. However, the specific plans of teaching activities are different in the use of flipped classroom teaching mode of different courses. In some course, the effect of study of the students in pre-class is bad, and the discussion between teachers and students in class can't go smoothly and causes a series of vicious circle.

In this paper, I apply the advantage of task-driven teaching in stimulating student's interest of study and the advantage of micro-lecture in improving student's attention into the flipped classroom. Based on the Robert Talbert flipped classroom model, I construct flipped classroom teaching model based on task-driven and micro-lecture showed in Figure 1.

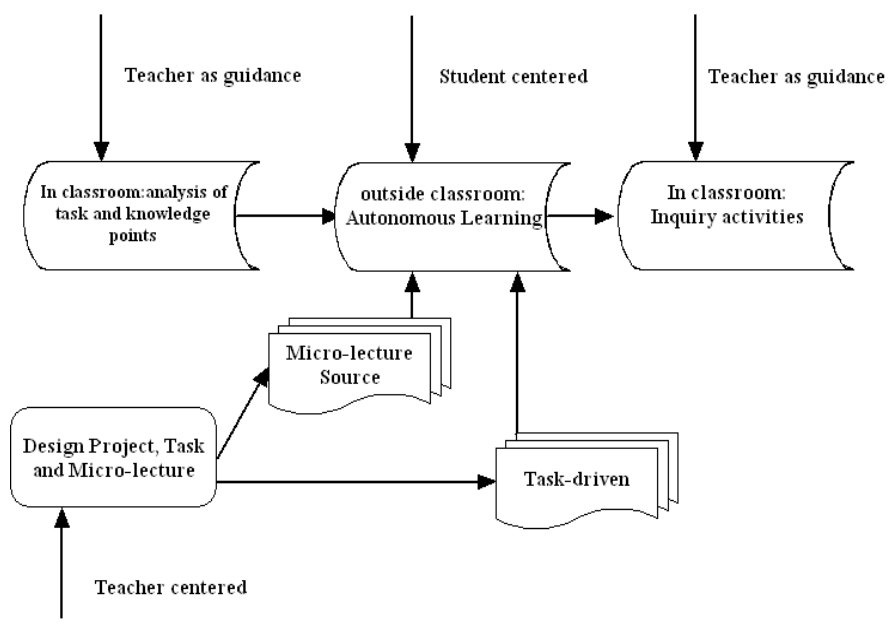

Figure 1. Flipped classroo teaching model based on task-driven and micro-lecture.

1) the design of the project, task and micro-lecture

a) the design of the project and task

The good or bad of task directly affects the whole effect of the teaching model. If the task too difficult, it will dampen the enthusiasm of students learning. Therefore too difficult task is unfavorable to the cultivation of their interest in computer. And if the task is too simple, it cannot achieve the purpose of the test students' knowledge level or develop students' thinking. It is to say that too simple task is unfavorable to the growth of the students. Therefore the task is too difficult or too simple has negative influence in teaching. So the design of the task should consider the level of students and the master degree of knowledge to design a flexible task which can be extended by students according to their abilities.

All the tasks of this course are not isolated, but interrelated and complementary to each other. And finally, all the tasks can be integrated into a project reflected in the form of a system or software. In order to stimulate students learning motivation and curiosity, all the tasks must be combined with actual project and interesting. The actual project can make students feel the project authenticity and practicality, attract the attention of students, and enhance the initiative of students to complete the project. In addition, on the basis of the actual project, all the tasks should integrate with the teaching content of course. Through the project, students will be able to realize the importance of the course in social work practice. This solves the student study purpose is not clear in class learning and learning initiative is poor.

The project is in made up of a number of typical tasks. Task-driven teaching divides the teaching content into some units, and guides students to master the knowledge with typical task. Through the task teaching, students can combine theory and practical, and realize the practical application of knowledge clearly. It forms an integration of theory and practice which namely "3W1H (3W stands for 
What, Why and Where, $1 \mathrm{H}$ stands for How) "[2]. It is an iterative, cyclical process of task teaching, knowledge induction, practice case, summary and evaluation. What's more, it's an effective teaching method which can improve teaching effectiveness and train vocational skills.

\section{b) Production of Micro-lecture Resource}

The core composition content of micro-lecture is microvideo which is different from traditional video recording of classroom teaching. A micro-video can be one or two knowledge points, a case or a concept and also be a problem solution, teaching reflection and so forth. The theme should be made clear while every micro-lecture was produced. The theme of micro-lecture comes from the basic knowledge corresponding to tasks, demonstration of tasks and the implementation of the tasks. Sometimes, different microlecture should be recorded with a same problem, so the customized micro-lecture can fit different foundation of student.

Each independent micro-video are not unrelated, the knowledge points exist more or less contact between them. The knowledge points are too many which requires teachers make an explicit relationship between the micro-lecture knowledge and specific tasks. Teachers should organize the micro-lecture resources to form the structure system corresponding to tasks of project and help the students to finish the self-study driven by tasks of project.

\section{2) Task and Knowledge points analysis in classroom}

\section{a) Group cooperation}

Teacher organizes the students into several heterogeneous study groups or collaborative learning group according to its academic level, aptitude, personality traits. In each study group, the students who are good at programming and are interested in programming will drive and infect other classmates. In the process of group cooperation, good students make their own knowledge mastery through a comprehensive study; Poor interest student can also get encouragement and help in the collaborative learning.

b) The analysis of task and knowledge points

Teacher demonstrates the task and put forward the concrete requirements needed to complete the task. Through the demonstration, students can clear and definite the objective of the task. And then teacher organizes students to analyze and discuss the task and find out the basic knowledge needed to complete the task.

By analyzing the task, students have accurate cognition about How to complete the task. Moreover the students can be more clearly about the requirements and effect to learn the new knowledge content.

3) Learning with micro-lecture implementating the tasks outside the classroom

In practice, the students driven by task to look up the textbook, the library resources and watch the micro-videos teachers have prepared to achieve the self-study of basic knowledge, as well as complete implementation of tasks within the required time. During this process, group students are required to play a team spirit, mutual communication and mutual cooperation. The teachers encourage students to accomplish tasks by self-study, group cooperation. With the help of task and knowledge point's analysis in first stage, the students carry out autonomous learning effectively. Moreover, when the required knowledge beyond the knowledge structure of students, the teacher works as a leading role who help students to solve problems or give solution and bibliography, avoiding students producing "technical barriers". Therefore this stage take "task driven" as the main line, "group cooperation" as the means, the teacher as the leadership, the student as the main body to complete the study of basic knowledge and tasks.

4) Knowledge degestion and absorption

The objective of classroom activities is to complete the process of knowledge digestion and absorption. Classroom activities were arranged in computer room according to the practical features of JAVA programming. Firstly, teacher explains most of the content which students puzzled in a short period of time during the classroom activities, and review of knowledge through simple practice. Each group may encounter some questions in the process of cooperation to complete the task or problem solving, then the teacher should give each group students personalized guidance, help them to solve the problem. In the end of classroom, teachers should point out the difficult point of course knowledge and comb systematically the course of knowledge to achieve the construction and internalization of knowledge and skill.

5) Evaluation and extention of tasks after classroom

Teacher should give a comprehensive analysis for the student according to the progress of learning, the complete of basic knowledge questions and learning habits. On the basis of it, teacher gives positive suggestions and specific guidance in self-study of student. At the same time, exchange activities of JAVA Programming design achievement should be carried out. In these activities the students could develop task results, results of exchanges, and mutual evaluation. Teacher pointed out the bugs may exist of the task, and make into a micro-lecture. Some students that learning ability is weaker could learn repeatedly, strengthening the knowledge absorption process through .the mobile terminal. Moreover, teachers should collect the teaching content related development learning resources and design extensional tasks. The student that learning ability is stronger can challenge the development task, achieve student to consolidate and develop the knowledge (skill). Paying attention to the differences of students, teacher should put forward the appropriate basic assessment index and development assessment index. Basic assessment can be achieved through work-hard by every student, whereas the development assessment index encourage student to use extra-curricular knowledge to improve and perfect the task, so as to cultivate students actively explore, bold pioneering spirit. 


\section{The PRACTICE OF "FliPPED ClASSROOM” TEACHING MODEL BASED ON TASK-DRIVEN AND MiCRO-LECTURE}

\section{A. Practice program}

In order to check the maneuverability and the implementation effect of "Flipped Classroom" teaching model based on task-driven and micro-lecture, this paper take the teaching content "class and object" of JAVA programming as example to carry out the practice study of "flipped classroom" teaching model based on task-driven and micro-lecture. For undergraduates of grade 2011 in department of computer, the "Java programming" course is carried out by flipped classroom pattern (figure 1). This course contains 56 class hours, reasonable arrangement of course content: face-to-face teaching and online teaching, according to the specific condition. In addition, use the method of questionnaire and interviews to know the attitude of the learner to new model and the change of students' learning interest compared with the traditional model.

\section{B. Implement of proctice program}

\section{1) The design of task}

Design and implement "student address list" system. The system is comprised of "add", "delete", "modify", "find" etc. And then three students are grouped in each group according to the situation of the students' learning interesting.

2) The analysis of task and knowledge points

The teacher organize the students to analysis the task and the required knowledge points. System can apply character interface and contain a main interface to select "add", "delete", "modify", "find" function according to the prompt. In order to realize the system, there are two classes required to system: A class is main interface which is used to receive input from the user and make relevant response. Another class is the student class which contains students' properties and method. Student information can use array or list to store. According to the requirements of the task analysis the knowledge point required to complete the task is given as follows: class to create, create and use objects, an array or a list of storage.

\section{3) Production of Micro-lecture Resource}

Recorded five micro-video which respectively explained the

" the concept of class and object", "the method and illustration of creating class", "the method and illustration of object's use", "the definition and use of array or list" and "illustration of task".

4) According to the analysis of task and knowledge, students self-study the basic knowledge, basic skills, and complete the task on the basis of the implementation so as to realize in practice the "classes and objects" the digestion of knowledge and master.

5) According to student feedback and some difficulties in task implementing, the teacher organize student to discuss the important knowledge points and difficult knowledge points, such as the knowledge about the use of list. And then teacher further summarizes the knowledge and to further explore the expansion of application.

\section{The effect of "flipped classroom" teaching model based on task-driven and micro-lecture}

\section{1) The results of self-study before classroom}

Question 1: "Whether the design of task and the analysis about task and knowledge is helpful to your self-study outside the classroom and the degree of help?"

The results of the survey show that $80 \%$ of students thought that it is very useful to promote and guide their selfstudy; $95 \%$ of the students thought it is helpful to their autonomous learning before classroom.

Question 2: "Depending on self-study and group cooperation, whether task can be completed?"

The results of the survey show that $100 \%$ of students can complete the basic goal of task by self-study and group cooperation; $60 \%$ of the students is interested to the extension goal of task.

Question 3: "How much time do you spend in studying the micro-lecture?"

The results of the survey show that nearly half of all students spend time in about 30 minutes, while the top $10 \%$ of students spend time in about 20 minutes and the bottom $15 \%$ of students spend time in about 50 minutes. It fully confirms flipped classroom plays a positive effect on hierarchical teaching.

2) The survey about the acceptance of "flipped classromm" teaching model based on task-driven and micro-lecture.

The results of the survey show that $23 \%$ students thought that this teaching mode is very good, $47.5 \%$ thought this model is good, only $29.5 \%$ thought this model is just ordinary model, no students thought that the model makes the learning becomes poor; The corresponding is $78 \%$ of the students like to use this model, no students object to use the model. This suggests that the student to this teaching model has a high acceptance.

\section{CONCLUSION}

It is of great significance to carry out flipped classroom for software and related course in college. In view of problems in self-study before classroom, such as objective, enthusiasm and learning concentration, this paper give the "flipped classroom" teaching model based on the task-driven and micro-lecture. It is a more effective teaching method for learning the Java programming course and it breaks through the traditional teaching mode. Students have a sense of achievement and the spirit of exploration during the process of learning. Through the guide of task, students not only learn much in project development process, in order to master the knowledge, but also improve the ability to solve practical problems. Meanwhile, it plays a positive role in promoting students' teamwork, innovation and practical ability. 


\section{REFERENCES}

[1] Robert Talbert. Inverting the Linear Algebra Classroom [DB/OL].[2013-01-20]. http://prezi.com/dz0rbkpy6tam/inverting-thelinearalgebra-classroom.

[2] Randall S. Davies, Douglas L. Dean, Nick Ball. Flipping the classroom and instructional technology integration in a college-level information systems spreadsheet course[J]. Educational Technology Research and Development,2013,(4): 563-580.

[3] Gregory S. Mason, Teodora Rutar Shuman, Kathleen E. Cook. Comparing the Effectiveness of an Inverted Classroom to a
Traditional Classroom in an Upper-Division Engineering Course[J]. IEEE Transactions on Education, 2013,(4): 430-435.

[4] J. L. Cen and T. S. Hu, "Micro-lecture: a new form of digital teaching resource”, Education Information Technology, (2013), vol. 4.

[5] Bo Liu, Yue Shen, Ying Zeng, "Research on the Driving Teaching Pattern by Computer Projects in Colleges," Computer Education, No.4, pp.82-84, 2011.

[6] T. F. Yao, Practice of introducing computational thinking into programming course, Journal of China University Teaching, vol. 2, pp. 61-62, 2012. 